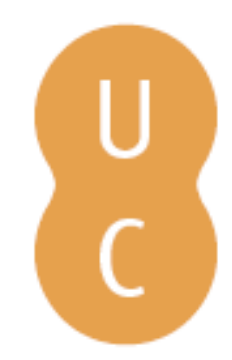

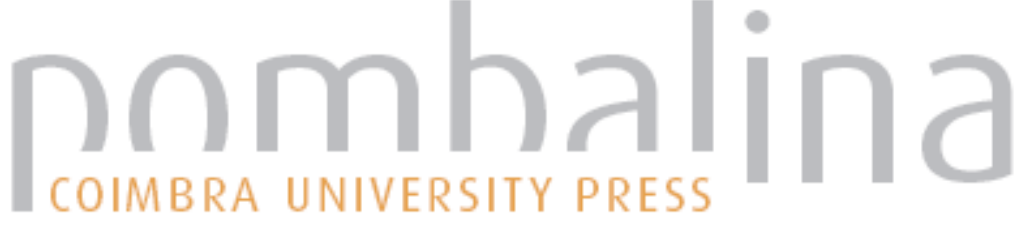

\section{A expressão dramática no ensino da língua inglesa}

\author{
Autor(es): $\quad$ Marta, Eva \\ Publicado por: Imprensa da Universidade de Coimbra \\ URL \\ persistente: URI:http://hdl.handle.net/10316.2/35916 \\ DOI: $\quad$ DOI:http://dx.doi.org/10.14195/978-989-26-0690-3
}

Accessed : $\quad$ 26-Apr-2023 03:12:05

A navegação consulta e descarregamento dos títulos inseridos nas Bibliotecas Digitais UC Digitalis, UC Pombalina e UC Impactum, pressupõem a aceitação plena e sem reservas dos Termos e Condições de Uso destas Bibliotecas Digitais, disponíveis em https://digitalis.uc.pt/pt-pt/termos.

Conforme exposto nos referidos Termos e Condições de Uso, o descarregamento de títulos de acesso restrito requer uma licença válida de autorização devendo o utilizador aceder ao(s) documento(s) a partir de um endereço de IP da instituição detentora da supramencionada licença.

Ao utilizador é apenas permitido o descarregamento para uso pessoal, pelo que o emprego do(s) título(s) descarregado(s) para outro fim, designadamente comercial, carece de autorização do respetivo autor ou editor da obra.

Na medida em que todas as obras da UC Digitalis se encontram protegidas pelo Código do Direito de Autor e Direitos Conexos e demais legislação aplicável, toda a cópia, parcial ou total, deste documento, nos casos em que é legalmente admitida, deverá conter ou fazer-se acompanhar por este aviso.

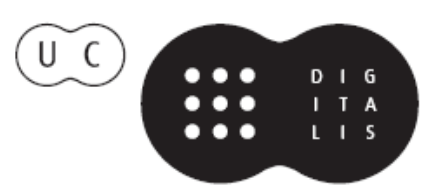




\section{O CRUZAMENTO DE SABERES NA AULA DE INGLÊS}

CONTRIBUTOS PARA UMA PRÁTICA MULTIDISCIPLINAR

ANA R. LUÍS COORD.

IMPRENSA DA UNIVERSIDADE DE COIMBRA COIMBRA UNIVERSITY PRESS 
Drama is powerful because its unique balance of thought and feeling makes learning enjoyable, exciting, challenging and relevant to real-life concerns.

WAGNER 1999:5

\section{Introdução}

Com este artigo, pretende-se demonstrar que o recurso a Atividades de Expressão Dramática (AED), tais como o jogo dramático, a mímica, o role-play, a simulação e a improvisação, permitem motivar os alunos para a aprendizagem da Língua Inglesa bem como contribuir para o desenvolvimento das suas competências comunicativas e do seu desenvolvimento social.

Segundo Landy, (1982:5 apud Athiemoolam 2004:4) os elementos do drama, tais como a imitação, a imaginação, o role-playing e a interpretação, poderão levar a que uma criança aprenda uma língua, movimentos e até comportamentos sociais. Ao interpretar o papel de mãe ou pai por exemplo, a criança aprende o que é ser um progenitor, bem como o que se espera dela na sua relação com os seus pais. Assumindo o papel de outra pessoa, os alunos "envolvem-se através da construção das personagens em outros modos de pensar e agir num processo de questionamento do seu olhar sobre si mesmo e sobre os outros" (Melo 2006:1). Ao idealizarem determinadas situações, ainda que imaginárias, os alunos são convidados a explorar outras atitudes, opiniões, experiências, que os poderão ajudar a perceber melhor determinados conceitos. Wessels (1987:7) apresenta o seguinte exemplo: 
If a learner of English ask you 'what is a blind person?' You might simply reply. 'A blind person cannot see' and this would probably satisfy him intellectually. But if you replied, 'Shut your eyes and try to find your pen on the desk in front of you', you would be involving him in the actual experience of being blind, and would thus satisfy him not only intellectually but emotionally as well.

As atividades dramáticas exigem alguma imaginação por parte dos seus participantes. Ao pedirmos a um aluno que, por exemplo continue uma história ou que proponha uma alternativa, estamos a estimular a sua imaginação e o seu intelecto (Wessels 1987:8). Ao participarem em atividades dramáticas, os alunos formulam hipóteses, fazem sugestões, especulam e analisam situações, ou seja, colocam questões para as quais terão que procurar respostas, o que poderá ajudar os alunos a desenvolver a sua capacidade de raciocínio (Athiemoolam 2004:4) e, consequentemente, a aprender de forma indutiva.

Segundo uma perspetiva cognitivista da aprendizagem, os alunos aprendem, assim, de uma forma ativa, participando "mentalmente, nos diferentes momentos da transformação da informação até que ela possa ser armazenada sob a forma de conhecimento ou utilizada na resposta a um problema ou a uma tarefa de natureza cognitiva" (Mayer, 1999 apud Festas 2007). Também Festas (2007) defende que a principal preocupação do ensino e educação deve precisamente ser a de "ajudar os alunos a ser cognitivamente ativos”. A autora acrescenta que, se os alunos forem capazes de "selecionar, organizar, integrar, armazenar e recuperar o conhecimento", estão criadas as condições para uma "aprendizagem eficaz" e é precisamente isso que acontece ao envolverem-se numa AED.

Wessels (1987) também concorda com a ideia de que o envolvimento dos alunos nas atividades torna as memórias da aprendizagem mais duradouras. Para o autor, qualquer tipo de aprendizagem envolve uma situação, um problema e uma solução - uma realidade superficial - mas envolve também um contexto prévio, emoções e planos - uma realidade subjacente. Segundo Wessels, o grande erro da maioria dos professores é o de providenciarem aos seus alunos apenas a realidade superficial da situação. Talvez por esse motivo os alunos se esqueçam tão facilmente 
do que lhes é ensinado. Contudo, ao permitir ao aluno que este conheça o contexto prévio de determinada situação ou que explore as emoções envolvidas estamos a permitir que este aprofunde a sua perceção. Se, por exemplo, perguntarmos a um aluno como é que ele acha que a personagem se sente ou como é que ele se sentiria no lugar da personagem, estamos a desbloquear os sentimentos do próprio aluno em relação à personagem e/ou à situação em questão (Wessels 1987:7). Ao mesmo tempo estamos a permitir que o aluno faça uso do conhecimento prévio que possui, seja em termos de vocabulário adquirido, seja em termos de experiências vividas, e que o relacione com a situação a tratar.

As AED são também uma forma de ensinar, rever e/ou consolidar conteúdos curriculares. Segundo Kao \& O'Neil (1998:3), as AED têm sido utilizadas, por exemplo, para explicar acontecimentos históricos, ou para elaborar uma personagem ou situação em literatura. Os autores consideram que é possível incorporar atividades dramáticas, em várias áreas disciplinares, para atingir determinados objetivos curriculares, uma vez que o "drama é poderoso na aprendizagem que não diz respeito apenas ao crescimento pessoal, mas que envolve também questões morais, sociais e políticas."

\section{As AED no Ensino de Inglês}

No contexto do ensino do Inglês, Harmer (2007:352) afirma que atividades como role-play ou simulação podem ser bastante proveitosas para os alunos, pois estes têm a oportunidade de simular uma situação passível de acontecer na vida real. Estas situações podem ser representadas pelos alunos como sendo eles próprios em determinados contextos, ou vestindo a pele de uma outra personagem, expressando pensamentos e sentimentos que o aluno poderá não partilhar. Também Ur (1991:131) considera que, através do role-play podemos dar aos nossos alunos a oportunidade de utilizar a linguagem falada na sala de aula, como se se tratasse de uma situação "da vida real". Justamente, um dos principais objetivos das AED na aula de língua estrangeira é o de criar nos alunos 
a "necessidade de falar" (Wessels 1987:9), ao focarem a sua atenção na criação de diálogos, na interpretação de situações ou na resolução de determinados problemas da vida real. Quando há uma necessidade de falar, quando interagimos "na vida real" o nosso discurso é marcado por hesitações, interrupções, distrações, e até silêncios, sendo também influenciado pela relação que temos com a outra pessoa envolvida. Segundo Maley e Duff (1985:8-9), as pessoas com as quais falamos diariamente têm ocupações, sentimentos, preocupações, falam depressa ou devagar, i.e. cada um tem as suas peculiaridades, assim como nós, e, para comunicarmos com essas pessoas, temos que saber quem elas são e quem nós somos, bem como conhecer o contexto em que essa comunicação ocorre. Com as AED, pode enriquecer-se um pouco a língua com o aspeto emocional que normalmente fica esquecido, pois a língua não se resume a palavras, e essas poderão não ter qualquer significado para o aprendente de uma língua, se este desconhecer o contexto em que elas ocorrem.

Um diálogo, para além das hesitações, dos silêncios e das pausas, da linguagem corporal, envolve expressões faciais e/ou sons não-verbais, que podem ser tão eloquentes quanto as palavras. Todos estes elementos influenciam o discurso e a comunicação e caracterizam o que Wessels (1987:11) denomina "comunicação genuína" (genuine communication). Esta "comunicação genuína” é, na opinião do autor, frequentemente negligenciada por muitos manuais tradicionais, que oferecem diálogos repetitivos com sequências fixas e artificiais de tipo "A/B/A/B/A/". Maley e Duff (1985:8) também consideram que inúmeras capacidades envolvidas na utilização de uma língua são esquecidas pelos manuais tradicionais. São elas a capacidade de adequação, capacidade de reação, o tom adequado, a compreensão e a "previsão" das intenções comunicativas. Ladousse (1989:6), com o objetivo de salientar a necessidade de preparar os alunos para lidar com a natureza imprevisível da comunicação conta a seguinte história:

Did you ever hear the story of the student who had completed level three of his text book dialogue course and went to England to try out what he knew, only to find he never needed those beautifully formulated sentences to ask 
for half a pound of bananas, as he just helped himself in the supermarket? But he was completely floored at the checkout when the cashier said with a friendly smile, 'Got the $5 \mathrm{p}$, have you, dear?

Embora a principal ênfase das AED pareça incidir sobre as competências orais, estas podem, ser utilizadas para desenvolver outras competências linguísticas. Segundo Wessels (1987:9), os alunos são participantes ativos, utilizando a sua imaginação e interagindo uns com os outros. Os alunos falam entre si, comunicam, escutam-se, lêem textos e, por vezes, são eles próprios responsáveis pela produção escrita do texto a representar.

Além do treino das competências linguísticas, as AED têm um papel igualmente importante na aquisição de uma pronúncia, ritmo e entoações corretas, bem como no desenvolvimento da capacidade de adequação, capacidade de reação, a adoção do tom adequado, a compreensão e a "previsão" das intenções comunicativas, uma vez que todos estes elementos, fazendo parte da comunicação e dos diálogos da 'vida real' são também tidos em conta.

Poderão ainda existir componentes não-verbais, relacionadas com a realidade cultural do aluno, que podem igualmente beneficiar das AED. Os alunos de uma língua estrangeira poderão sentir dificuldades em adotar e/ou perceber determinados comportamentos de um habitante do país onde se fala a língua-alvo. Tomemos como exemplo determinados comportamentos associados à linguagem corporal. Para um aluno português que esteja a aprender Inglês, será certamente importante saber que, normalmente, no Reino Unido, a maioria das pessoas não se cumprimenta com "dois beijinhos" na face, mas sim com um simples aperto de mão. Estamos, portanto, a falar de uma abordagem cultural que deve ser tida em conta. O facto de os alunos realizarem determinada ação pode ajudá-los a compreender melhor as diferenças culturais entre o seu país de origem e o país, ou países, onde se fala a língua-alvo. Poderemos, assim, inserindo os elementos de aprendizagem num contexto realista e/ou com significado, proporcionar aos nossos alunos um enriquecimento não só linguístico, mas também cultural. 
A utilização de AED envolve a maior parte dos aspetos mencionados, conseguindo assim oferecer aos alunos situações comunicacionais genuínas, para além de o fazer de forma lúdica, interativa e interessante. Este carácter lúdico das AED potencia o uso deste tipo de atividade como ferramenta de ensino de estruturas e vocabulário e ainda de revisão e consolidação destes. Apresentar ou rever uma estrutura gramatical através de uma AED será certamente mais interessante e motivador para o aluno, não esquecendo porém que, embora seja importante o ensino das estruturas, é igualmente importante que estas sejam ensinadas num contexto com significado para o aluno. A mímica, por exemplo, permitiria rever e/ou consolidar tópicos gramaticais, como os tempos verbais. Por um lado, os alunos estão envolvidos de forma ativa na criação de uma dramatização, na qual poderão estar presentes várias formas de comunicação exceto a palavra. Por outro lado, o carácter lúdico da tarefa funciona como motivação à participação e, consequentemente, à aprendizagem, fazendo da aprendizagem da nova língua uma experiência agradável. Segundo Richard Via (1972 apud Wessels 1987:13), um dos pioneiros da utilização das AED no ensino de línguas estrangeiras, os alunos envolvem-se mais com a atividade de dramatização do que com a tarefa de aprendizagem da língua. Assim, segundo o autor, os alunos aprendem fazendo.

Wessels (1987:29) considera também que as repetições que se fazem aquando da memorização de um diálogo, por exemplo, envolvem os alunos num processamento profundo da língua. Além disso, permitem ainda um treino intensivo da pronúncia, ritmo e entoação, características às quais, normalmente, se dedica pouco tempo. $\mathrm{O}$ autor acrescenta ainda que a familiarização com o texto pode levar a uma maior fluência oral.

Finalmente, mas não menos importante, as AED contribuem para a melhoria da autoestima e autoconfiança do aluno envolvido. Por um lado, os alunos sentem-se mais à vontade quando podem 'vestir a pele' de outras pessoas. Ao pensar e agir como outro, o aluno fá-lo de uma forma mais livre do que faria se tivesse que agir como indivíduo, pelo que sente mais confiança na sua intervenção. Wagner (1999:12) defende que os alunos se sentem mais seguros quando se podem esconder atrás de uma máscara. Desta forma, os alunos podem 'aventurar-se' em situa- 
ções que, em qualquer outro contexto de sala de aula, poderiam ser perigosas. Os alunos podem representar, de forma simbólica, os seus próprios sentimentos, atribuindo-os à personagem. Sentem que podem falhar, pois estão a criar uma personagem fictícia, à qual podem atribuir a responsabilidade do insucesso.

Também Athiemoolam (2004:6) considera que a improvisação, por exemplo, motiva os alunos a ser participantes ativos em situações realistas, reduzindo assim a sua autoconsciência. Segundo o autor, os alunos poderão sentir-se inibidos em fases iniciais, mas após algumas sessões tornar-se-ão mais entusiastas e será visível um grande desenvolvimento da sua autoconfiança. Além disso, os nossos alunos poderão ter outras aptidões para além das suas competências linguísticas: um aluno poderá ter algumas dificuldades face à aprendizagem de uma nova língua, o que o pode fazer sentir-se desmotivado, mas ter outras aptidões, tais como aptidões para a dança ou a representação (Wilson 2010:10). Mesmo não dominando a língua, o facto de ter oportunidade de atuar na aula de língua estrangeira (e ter uma boa prestação, mesmo que esta não seja a nível linguístico), dará ao aluno um maior sentimento de confiança, motivando-o. Os alunos poderão não dominar a língua estrangeira, mas o facto de terem a oportunidade de a utilizar, treinando-a e com isso melhorando as suas competências, é uma condição para a motivação.

Trabalhando em grupo, os alunos discutem, negoceiam e tentam chegar a um consenso. Por outras palavras, os alunos interagem, desenvolvendo assim competências de interação grupal (Athiemoolam 2004:5), bem como todos os aspetos da sua personalidade. Alunos mais tímidos, ou menos participativos, tendem a libertar-se mais quando estão em grupo, pois a atenção não recai sobre eles apenas, mas sim sobre todo o grupo. Por outro lado, mesmo que participem de forma menos 'manifesta', terão tido oportunidade de agir e de se divertirem com a atividade tal como os restantes. Segundo Maley e Duff (1985:29), os alunos mais tímidos começam a ganhar autoconfiança quando trabalham com um parceiro ou em pequenos grupos, especialmente se são incentivados ou elogiados.

Em suma, retiram-se evidentes benefícios a partir da utilização das AED na aula de língua estrangeira: de forma interativa e contextualizada, 
as AED contribuem para o desenvolvimento de competências orais, tais como a pronúncia, a prosódia e a entoação; para a aquisição ou consolidação de vocabulário, estruturas e de conteúdos culturais; através do envolvimento dos alunos, as aprendizagens revelam-se mais duradouras; as AED potenciam, ainda, o desenvolvimento da autoconfiança do aluno, bem como da sua motivação face à aprendizagem da língua estrangeira.

\section{Tipos de Actividade de Expressão Dramática}

Nesta secção, serão apresentados alguns tipos de AED, nomeadamente, o jogo dramático (3.1), a mímica (3.2), o role-play (3.3), a simulação (3.4) e a improvisação (3.5), e serão ilustradas algumas técnicas que permitem explorar cada uma das AED no contexto da aula de Inglês.

\subsection{O jogo dramático}

Comecemos por explicar o que se entende por 'jogo dramático' (drama games). Segundo Wessels (1987:29-30), o jogo dramático é um tipo de atividade que envolve ação e movimento: os alunos são convidados, por exemplo, a andar pela sala de aula, a investigar as características físicas desta e a comunicar com o maior número possível de pessoas. Este tipo de AED exercita a imaginação: os alunos são chamados a inventar novas situações ou a reinventar situações já existentes com as suas próprias ideias dando voz aos seus pensamentos. O jogo dramático permite, ainda, a expressão de emoções através de meios linguísticos e paralinguísticos: o aluno ao criar empatia com a situação ou personagem que representa, tem liberdade para expressar uma variedade de emoções não só no discurso, mas também através de expressões faciais e gestos. São estes elementos que, segundo o autor, distinguem o jogo dramático dos convencionais "jogos de estruturas" (structure games) na aula de Inglês que, tal como o próprio nome indica, são utilizados para treinar estruturas apenas, não havendo espaço para outros aspetos da linguagem. Embora 
estes jogos de estruturas sejam eficazes, quando a estrutura em questão é compreendida, ou aprendida, a tendência é a de que estes se tornem repetitivos e sem interesse. Com o jogo dramático, é possível criar um âmbito mais alargado e apelativo, logo menos repetitivo. Além disso, o jogo dramático contempla todos os aspetos da linguagem, tais como os gestos, sentimentos, volume, entoação e até pausas e hesitações, que normalmente são 'esquecidos' pelos jogos de estruturas.

Relativamente à preparação do jogo dramático, nem todos os jogos necessitam do mesmo nível de preparação por parte dos alunos como, por exemplo, a leitura de textos ou a introdução de vocabulário específico necessário para a atividade. Contudo, qualquer jogo tem regras que devem ser respeitadas para que o jogo tenha sucesso. $O$ mesmo acontece no ensino de uma língua e, para que um jogo seja feito de forma correta, essas regras devem ser claramente expostas e explicadas pelo professor. $O$ procedimento deve ser previamente esclarecido, para que os seus participantes percebam claramente os objetivos.

Na minha opinião, o jogo dramático é adequado, principalmente, para os níveis de iniciação, pois é importante criar situações que motivem os alunos a aprender a língua estrangeira. Através da utilização do jogo dramático, mesmo com poucos recursos linguísticos, os alunos podem conseguir produzir algo ou passar uma determinada mensagem que, possivelmente, noutro contexto de aprendizagem não conseguiriam. Porém, o jogo dramático também poderá ser utilizado em qualquer outro nível de aprendizagem e até mesmo em qualquer fase da aula, seja para introduzir, rever ou consolidar conteúdos. Wessels (1987) propõe alguns exemplos de jogos dramáticos que poderão ser utilizados para trabalhar diversas estruturas, em diversas fases da aula de Inglês. O autor demonstra ainda que, dependendo do objetivo que se pretende atingir, um mesmo jogo poderá ser utilizado no início da aula (starters), no intervalo de dois momentos (in-betweens) ou no final da aula (endgame). Neste sentido, fica claro que o jogo dramático é ajustável a vários níveis de aprendizagem e a diferentes momentos da aula. 


\subsection{A mímica}

O discurso oral vem sempre acompanhado de mímica (ou seja, linguagem corporal, gestos e de expressões faciais) que refletem as intenções do falante e, portanto, ajudam o ouvinte a compreender melhor a mensagem. Segundo Byrne (1986:116), ao usarmos mímica estamos a "performing actions without using words". Esta característica da mímica pode lançar algumas dúvidas sobre a sua relevância para o desenvolvimento das competências linguísticas, mas, conforme iremos mostrar, o uso da mímica permite aos alunos compreender que, na comunicação, não são apenas as palavras que veiculam sentido.

As atividades de mímica permitem estimular a imaginação: o observador tem que construir uma mensagem a partir de sinais visuais. Esta é uma tarefa tão relevante para aqueles que têm de comunicar através dos gestos, como para aqueles que tentam interpretar esses gestos (Maley \& Duff 2005:50). Para além do estímulo da imaginação, a mímica tem outras vantagens, uma vez que envolve a utilização de diferentes canais sensoriais (visuais e cinestésicos) como forma de apoio à expressão oral. Trata-se de uma "consciencialização da língua" (language awareness) que, segundo Byrne (1986:116), pode ser feita através de atividades simples: podemos, por exemplo, pedir aos alunos que trabalhem em pares ou pequenos grupos e que representem uma determinada ação, tal como: comer, ler, partir um objeto, cortar um objeto. O autor defende que é essencial que os alunos tenham uma ideia precisa sobre o objeto, a pessoa ou situação que deve ser representada, uma vez que este elemento será eventualmente o motivo que levará os alunos a falar, quando tiverem que contar aos outros elementos o que estão a representar. Desta forma, uma atividade sem palavras acaba por conduzir à oralidade: "Wordless activities, then, lead quite naturally to talk".

Byrne (1986:117) sugere ainda outras atividades que conduzem ao “role-play sem palavras". Vejamos alguns exemplos:

a) ask the students to work in situations where there are not only actions but also probably some show of feeling. For example: 
- two people sharing a table

- two people sharing some food

- two people sharing an umbrella

- two people sitting next to one another

b) ask the students to work in small groups (e.g. 5-6) meeting one another

- as themselves

- in different roles e.g. as friends/ strangers

- in different moods e.g. cold/ friendly

- with different reactions e.g. surprise/ fear.

Algumas destas atividades poderão exigir alguma preparação prévia: é importante que os alunos tomem consciência de aspetos, tais como, o local onde estão, quem são e qual a relação existente entre os vários elementos. É essencial que a atividade seja posteriormente sujeita a uma discussão que promova a participação oral dos alunos.

\subsection{Role-play}

O role-play é, talvez, a AED mais utilizada nas aulas de Inglês. Segundo Ladousse (1989), embora seja difícil distinguir entre role-play e simulação, as simulações são claramente mais complexas e demoradas. Embora incluam o elemento de interpretação de papéis, envolvem, ainda, outros elementos, tais como análise de dados, discussão de opções, conforme veremos na secção seguinte. Também Byrne (1986:117) considera que com o role-play, podemos oferecer aos alunos duas opções: por um lado, podem agir como eles próprios numa situação imaginária; por outro, podem agir como outra pessoa numa situação imaginária. Neste último caso, os alunos terão, por vezes, que interpretar papéis que não são diretamente relevantes para eles (Byrne 1986:117-118).

Vejamos o exemplo de um diálogo num restaurante. Dois alunos deverão criar e/ou interpretar um diálogo entre um cliente e um empregado de mesa num restaurante. Dificilmente o aluno se encontrará, na vida real, no papel de um empregado de mesa, i.e., é mais provável que o aluno se 
identifique mais com o papel de cliente do que com o papel de empregado de mesa. Mas, por outro lado, o facto de se poder 'refugiar' sob uma 'capa', uma 'máscara', poderá fazer com que alunos mais introvertidos se sintam mais à vontade, sintam que podem falhar, uma vez que se trata da criação de uma situação fictícia. (Wagner, 1992:12). Assim, deverá o professor identificar as situações que estimulem os alunos, mas também atribuir-lhes papéis que vão ao encontro das suas necessidades e personalidades. É importante, ainda, que os alunos tenham a oportunidade de escolher, seja escolher aquilo que dizem ou a forma como interpretam a situação (Byrne 1986:117-119).

Byrne (1986) propõe uma série de atividades relacionadas com role-play, que dão ao aluno essa oportunidade de escolha: open-ended dialogues, mapped dialogues, role instructions e scenarios. Open-ended dialogues são utilizados para nos referirmos a diálogos, cujos finais terão que ser decididos pelos alunos, i.e. é dada a parte inicial do diálogo e os participantes devem decidir como é que a história continua. Mapped dialogues referem-se a situações de diálogo guiado, em que cada participante recebe um cartão com indicações, não havendo, no entanto, conhecimento das indicações existentes no cartão do outro participante. Nas role instructions, cada participante recebe um cartão que contém a informação sobre a situação e que lhe diz como devem interagir. Nos scenarios, é apresentada a sequência dos acontecimentos, sem que sejam dadas aos alunos as palavras utilizadas; esta apresentação pode ser feita através da descrição de uma situação ou através de uma sequência de imagens.

Byrne distingue ainda o scripted role-play, que designa qualquer atividade de role-play que envolva a interpretação de um texto. O autor considera que esta pode ser uma atividade difícil de concretizar, uma vez que os alunos têm que dar vida a um texto escrito e ainda trabalhar uma forma de interpretação que seja consistente com o texto. O scripted role-play distingue-se, pois, das atividades de tipo open-ended dialogues, mapped dialogues, role instructions e scenarios pelo facto de não permitir que os alunos criem o seu próprio texto.

A interpretação de papéis requer alguma preparação prévia. Jung (2001:190) propõe uma sequência de fases, das quais destaco as três fases 
seguintes: a preparação, a aplicação e a discussão/avaliação. Durante a fase de preparação, é identificado o tema, o objetivo da atividade e atribuem-se os papéis. Os alunos procedem ainda à recolha de dados para a dramatização e constrói-se o espaço cénico. Na fase da aplicação, é apresentada a dramatização de determinada situação sob a observação dos restantes elementos da turma que não participam na interpretação. Finalmente, segue-se a fase de discussão na qual se procede a uma avaliação da atividade, incluindo a interpretação e a adequação do vocabulário utilizado. Estas três fases, segundo Mattes (2002:46), são essenciais para que seja respeitada a função didática da interpretação.

\subsection{A simulação}

A simulação, segundo Byrne (1986:125-128), é uma atividade durante a qual os alunos discutem um problema no contexto de um cenário definido. Como vimos no capítulo anterior sobre o role-play, a simulação distingue-se pela sua complexidade e duração, e ainda por envolver elementos, tais como análise de dados e discussão de alternativas. Para Jung (2001: 201), a situação a representar é apresentada, mas não coberta em toda a sua extensão, ou seja, é dito aos alunos o que eles devem fazer (encontrar uma solução), mas não como devem fazê-lo. Numa simulação não há um diálogo escrito ou previamente elaborado, pois o objetivo será o de levar os alunos a encontrarem estratégias que permitam resolver um problema e, principalmente, tomar decisões adequadas. Neste sentido, a simulação envolve simultaneamente a capacidade de compreensão e a expressão linguística, para além de promover a cooperação e a capacidade argumentativa (Jung 2001:201). Por outro lado, não havendo texto a seguir, os vários participantes não sabem o que esperar uns dos outros. Portanto, esta é também uma atividade que também requer alguma improvisação e flexibilidade por parte dos seus intervenientes.

Jung (2001:201) defende que a simulação compreende três fases: a preparação, a implementação e a discussão. Durante a fase de preparação, cabe ao professor introduzir o tópico ou situação, formar grupos 
de trabalho e distribuir papéis. Na fase de implementação, procede-se à análise do ponto de partida, à recolha de informação e à atribuição dos papéis. Provavelmente, nem todos os alunos terão a oportunidade de participar, pelo que será importante atribuir tarefas aos alunos que ficam a desempenhar o papel de observador. Uma forma de o fazer é atribuir a esses alunos tarefas como tirar notas, responder a perguntas, anotar e relatar informação. Por fim, na fase de discussão, é feita uma avaliação da atividade. Num último momento, pode ainda ser feita a correção linguística dos erros que o professor recolheu durante a simulação.

Segundo Byrne (1986:128) a simulação é uma atividade que exige maior envolvimento do professor que, como mediador, deve ter os seguintes cuidados:

- Explicar de forma clara o que é uma simulação e o que se pretende com este tipo de AED.

- Auxiliar os alunos na fase anterior à simulação, podendo inclusivamente redefinir ou alterar papéis ou ajudar os alunos na sua interpretação.

- Promover, no final da simulação, uma discussão que permita colocar os alunos numa posição em que sejam capazes de avaliar a simulação em geral e a sua performance em particular e, ao mesmo tempo, corrigir alguns erros que tenha anotado durante a simulação.

É extremamente importante que os alunos estejam bem preparados e possuam informação suficiente, de modo a que não se sintam desorientados no momento de falar. Devido à sua exigência linguística, a simulação é, pois, uma AED que exige um nível intermédio ou avançado de conhecimento da Língua Inglesa.

\subsection{A improvisação}

As atividades de improvisação podem ser definidas como "um conjunto de ações espontâneas, sem guião e não ensaiadas" (Landy 1982:6 apud 
Athiemoolam 2004:7). Athiemoolam (2004:8) considera que a improvisação é uma excelente técnica para o ensino e aprendizagem de uma língua estrangeira, uma vez que através dela os alunos são participantes ativos em situações autênticas. $O$ autor defende que, mesmo que inicialmente os alunos mostrem alguma hesitação em participar nas atividades, depois de algumas sessões sentem-se mais estimulados, o que levará ao aumento da sua confiança e, consequentemente, a uma melhoria no uso da língua-alvo.

Ainda segundo a mesma autora, a improvisação envolve o estabelecimento de um contexto, cujo objetivo é o de informar os participantes onde eles estão e o que espera que eles projetem nas suas relações com as outras personagens. Ao conhecerem o contexto, os alunos poderão relacioná-lo com a sua experiência pessoal, ativando assim o seu conhecimento prévio. Ao mesmo tempo, a identificação com determinada situação poderá suscitar maior interesse e envolvimento na atividade. Assim, os participantes têm a liberdade de fazer as suas próprias contribuições, de forma espontânea, à medida que a atividade se desenrola.

Qualquer AED deve ser introduzida de forma gradual, de modo a que os alunos se familiarizem com esta. As atividades de improvisação, especialmente, devem começar com situações simples, de modo a que os alunos se habituem a fazer uso do diálogo antes de tentar situações mais ambiciosas, uma vez que, nestas atividades, os alunos não têm o apoio de um texto, nem de um guião.

\section{Possíveis problemas (e soluções)}

Atividades como o role-play ou a simulação são cada vez mais recorrentes nas aulas de língua estrangeira, contudo existe ainda alguma controvérsia quanto ao seu valor pedagógico (Mattes 2002:46). Por um lado, o que para uns é visto como parte integrante de uma aula, para outros

é apenas uma perda de tempo. Esta é uma opinião partilhada não só por professores, mas também por alunos, que por vezes não entendem o objetivo da utilização de tais atividades. Cabe, assim, ao professor planear 
meticulosamente as aulas que envolvam AED, para que os alunos não as considerem fúteis, desestruturadas e sem objetivos.

A justificar a descrença no valor pedagógico das AED, os professores alegam que não têm os conhecimentos necessários para dinamizar este tipo de atividades (Athiemoolam 2004:5) e salientam o risco de perderem o controlo da aula. No entanto, segundo Jung (2001:191), as reservas manifestadas pelos professores devem-se a uma planificação desadequada, a um controlo deficiente da turma e ainda ao excessivo domínio do professor sobre a aula. Se a aula for meticulosamente preparada e as atividades cuidadosamente monitorizadas, não se corre o risco de a aula se transformar num caos (Mattes 2002:47). Além disso, os alunos deverão ser informados de que estão a trabalhar com a finalidade de atingir determinado objetivo, dentro de um limite de tempo estabelecido. Para além de os ajudar a organizar as atividades de grupo, esta responsabilidade irá também ajudá-los a concentrarem-se na atividade. É importante que, no final da aula, os alunos se sintam satisfeitos por terem conseguido cumprir os seus objetivos. O professor deverá ainda ser capaz de reconhecer até onde pode ir com os seus alunos e escolher atividades que se adequem aos seus interesses e/ou dificuldades/ inibições.

Contudo, também os alunos podem manifestar objeções às AED. Poderemos encontrar alunos que participam entusiasticamente, mas poderemos também encontrar alunos que se recusam a participar, ou porque são verdadeiramente tímidos, ou porque não vêem qualquer utilidade neste tipo de atividades. É, por isso, importante dar ao aluno um papel central, através do qual seja responsabilizado pela sua aprendizagem. O aluno deve ser constantemente confrontado com a necessidade de usar a sua imaginação, fazer algumas pesquisas, oferecer alternativas e até apresentar soluções. Desta forma, o aluno poderá sentir que está a fazer algo, e ao fazê-lo, sentirá que está a aprender. Ter um "líder de grupo", por exemplo, dá aos alunos esse sentido de responsabilidade. Wessels (1987:24) propõe, ainda, o recurso a alunos mais cooperativos que possam exemplificar algumas atividades e auxiliar nos trabalhos de grupo. O autor defende ainda que o professor deve certificar-se de que 
cada grupo contém pelo menos um destes alunos, uma vez que a sua presença irá estimular a atividade de grupo.

Os alunos podem ainda alegar que não têm imaginação, que têm medo ou vergonha de atuar em frente aos colegas ou ainda que têm medo de errar. O que podemos então fazer para ajudarmos os alunos a superarem as suas dificuldades face às AED? Algumas das soluções propostas por Jung (2000:191) passam pelo desenvolvimento de tarefas apropriadas que orientem - e motivem - os alunos. Wessels (1987) fala em criar elos de ligação entre a experiência do aluno e a situação ou entre este e a personagem, ou seja, tornando importante e aproveitando a experiência do próprio aluno. Quando perguntamos ao aluno sobre a personagem desbloqueamos os seus sentimentos de empatia para com a personagem ou situação em questão; quando lhes pedimos para continuarem uma história, para fazerem uma pequena introdução ou oferecerem alternativas, estamos a estimular a sua imaginação e o seu intelecto (Wessels 1987:25-26).

A construção da personagem é também bastante importante para evitar alguns dos problemas atrás mencionados. É necessário que seja atribuído algum tempo ao aluno para poder fazer esta introspeção e seleção de conhecimentos prévios, para que, no momento de expor as suas ideias, se sinta mais preparado para falar e dar vida à sua personagem. Outra solução proposta consiste em fazer o aluno perceber que a aprendizagem tem também uma característica lúdica (Jung 2001:191) e que se pode aprender ao mesmo tempo que se desenvolvem atividades divertidas. É, pois, necessário que o aluno entenda qual o objetivo da atividade. Seja o de ensinar, rever ou consolidar conteúdos, ou o de terminar de forma mais leve uma aula mais intensa, deverá ser sempre corretamente esclarecido.

Finalmente, deve explicar-se ao aluno que os erros fazem parte do processo de aprendizagem (Jung 2001:191): se o aluno não falar, os erros não serão detetados; se os erros não são detetados, não poderão ser corrigidos e não haverá evolução na aprendizagem. Maley e Duff (1985) defendem que os erros devem ser tratados noutras aulas, pois os alunos devem ter a oportunidade de reagir de forma espontânea e de interagir com os colegas, sem o sentimento de que estão a ser observados e de 
que vão ser penalizados se errarem. Também Wilson (2010:9) defende que o professor não deve interromper uma atividade para corrigir um erro; deverá fazer uma nota mental deste e corrigi-lo mais tarde, não sendo necessário nomear quem cometeu o erro. O autor vai ainda mais longe, dizendo que, mesmo que o nosso primeiro impulso seja corrigir o aluno, devemos tentar não fazê-lo; devemos, sim, elogiar os participantes pelas suas ideias e imaginação, dando reforço positivo, e corrigir os erros mais tarde (Wilson 2010:12). Esta correção pode ser feita oralmente, ou escrevendo no quadro, sem nomear os alunos, fazendo com que os próprios alunos deduzam a correção. Poderá ainda ser elaborado um exercício de remediação na própria aula (caso o professor tenha previsto a sua necessidade) ou numa aula posterior (Ladousse 1989:15).

\section{Conclusão}

As AED têm provado ser uma mais-valia para as aulas de Inglês: a. permitem uma interação fluente, com significado, na língua-alvo; b. o treino da pronúncia e da prosódia de forma contextualizada e interativa (Wessels 1987); c. a aquisição, o treino e a consolidação do vocabulário e estruturas em contexto (Maley e Duff 1985). Mas, como já vimos, não é só a nível linguístico que o aluno se desenvolve. A sua participação e envolvimento numa AED também contribui para o aumento do sentimento de confiança do aluno na sua capacidade para aprender a língua-alvo (Maley e Duff 1985, Wilson 2010). Por isso, e para que resultem conforme o pretendido, todas as AED devem ser meticulosamente planeadas, cuidadosamente controladas e, acima de tudo, devem estar sempre concentradas nos objetivos pedagógicos da aula (Mattes 2002), sendo planeadas de acordo com as necessidades e características da turma.

O jogo dramático, a mímica, o role-play, a simulação e a improvisação são algumas técnicas com as quais podemos providenciar aos alunos situações em que poderão por em prática a língua-alvo, agindo como eles próprios ou como outras personagens, explorando assim experiências, sentimentos e pensamentos diferentes e alargando o seu leque de 
perspectivas. Desta forma, para além das competências linguísticas, o aluno desenvolve ainda as suas capacidades cognitivas, evoluindo, assim, linguisticamente e cognitivamente de forma lúdica e interativa.

\section{Referências}

\subsection{Bibliografia}

Byrne, Donn. 1986. Teaching Oral English. New Edition. Harlow, Essex: Longman. Harmer, Jeremy. 2007. The Practice of English Language Teaching. $4^{\text {th }}$ ed. Harlow, Essex: Pearson Longman.

JUNG, Lothar. 2000. 99 Stichwörter zum Unterricht Deutsch als Fremdsprache. Ismaning: Max Hueber Verlag.

KAO, Shin-Mei and Cecily O'NeILl. 1998. Words Into Worlds: Learning a Second Language Through Process Drama. London: JAI Press, Ltd.

LADOusse, Gillian Porter. 1987. Role Play. (Resource Books for Teachers). Oxford: Oxford University Press.

Maley, Alan \& Alan DufF. 1985. Szenisches Spiel und freies Sprechen im Fremdspracheunterricht: Grundlagen und Modell für den Unterrichtspraxis. 2. erw. Aufl. Ismaning: Max Hueber Verlag.

Maley, Alan \& Alan Duff. 2005. Drama Techniques: A resource book of communication activities for language teachers. $3^{\text {rd }}$ ed. Cambridge: Cambridge University Press.

MatTES, Wolfgang. 2002. Methoden für den Unterricht. 75 kompakte Übersichten für Lebrende und Lernende. Schöningh: Paderborn.

UR, Penny. 1991. A course in language teaching: practice and theory. Cambridge: Cambridge University Press.

WAGNER, Betty Jane. 1999. Building Moral Communities Through Educational Drama. London: JAI Press, Ltd.

Wessels, Charlyn. 1987. Drama (Resource Books for Teachers). Oxford: Oxford University Press.

Wilson, Ken. 2010. Drama and Improvisation (Resource Books for Teachers). Oxford: Oxford University Press. 


\subsection{Webgrafia}

Athiemoolam, Logan. 2004. Drama-In-Education and its Effectiveness in English Second/Foreign Language Classes. The First International Language Learning Conference (ILLC): Universiti Sains Malaysia. Consultado a 6 de maio de 2013, em http://www.zsn.unioldenburg.de/en/download/Logan_Malaysia_Conference.pdf FESTAS, Isabel. 2007. ENL (estudar nos livros) e PUP (pensar um pouco). Consultado a 21 de novembro de 2013, em http://dererummundi.blogspot.com/2007/08/ enl-estudar-nos-livros-e-pup-pensar-um.html

Melo, Maria do Céu. 2006. A Expressão Dramática e o conhecimento tácito: da criação artística à compreensão histórica de problemas sociais. In Actas do VII Colóquio sobre Questões Curriculares. Globalização e (des)igualdades: os desafios curriculares. Braga: Instituto de Educação e Psicologia (CIEd). 11061118. Consultado a 4 de julho e 2011, em http://repositorium.sdum.uminho. pt/bitstream/1822/10103/1/ExpDram\%C3\%A1tica-Compreens\%C3\%A30\%20 Hist\%C3\%B3rica.pdf 